\title{
Is it Unjustified to Perform Segmentectomy in Surgical Treatment of Lung Adenocarcinoma?
}

\author{
Hüseyin Fatih Sezer, $M D^{1 *}$; Aykut Eliçora, $M D^{1}$; Salih Topçu, MD $^{1}$ \\ 'Department of Thoracic Surgery, Kocaeli University Medical School, Kocaeli, Turkey
}

\begin{abstract}
Background: The aim of our study differs from similar studies since we compared superiority and similarity of segmentectomy performed for early-stage lung cancer over lobectomy in terms of clinical and oncological results.

Methods: The data from 294 patients who underwent anatomical resection due to primary lung cancer were retrospectively reviewed. Data from 99 patients who underwent lobectomy and segmentectomy due to early-stage lung adenocarcinoma were analyzed. Patients were divided into two groups: 84 patients undergoing lobectomy and 15 patients undergoing segmentectomy. Both groups were analyzed in terms of epidemiological, surgical and oncological results, by comparing several parameters. Results: The most common postoperative complication was observed in the respiratory system. In total, 25 complication (29.8\%) in the lobectomy group and 3 complications $(20 \%)$ in the segmentectomy group were observed related to the postoperative respiratory system $(P=0.546)$. There was no statistically significant difference between the two groups in terms of recurrence-metastasis during follow-up, chemotherapy-radiotherapy condition and mortality. Main discharge time and thorax drain termination time were shorter in the segmentectomy group $(P=0.011$ and $P=0.033$, respectively). There was no statistically significant difference between the two groups in terms of postoperative survival or disease-free time ( $P=0.361$ and $P=0.461$, respectively).

Conclusion: If there is no contraindication, segmentectomy can be considered as the surgical treatment for lung adenocarcinomas with tumor size of $2 \mathrm{~cm}$ or less and a minimum $1 \mathrm{~cm}$ clean surgical margin.

Keywords: Adenocarcinoma, Lobectomy, Segmentectomy

Cite this article as: Sezer HF, Eliçora A, Topçu S. Is it unjustified to perform segmentectomy in surgical treatment of lung adenocarcinoma? Arch Iran Med. 2021;24(6):487-495. doi: 10.34172/aim.2021.70
\end{abstract}

Received: June 15, 2020, Accepted: November 16, 2020, ePublished: June 1, 2021

\section{Introduction}

Surgery is the primary treatment for early-stage non-small cell lung cancer. ${ }^{1-4}$ Lobectomy is accepted as the surgical treatment. ${ }^{5}$ In parallel with developments in radiological imaging methods, increase in detection of small-sized lung tumors, especially adenocarcinoma histopathological type, ${ }^{6}$ interest has increased in sublobar resections. ${ }^{1,-9}$ Therefore, the role of segmentectomy in the surgical treatment of early non-small cell lung cancer has become controversial.

The aim of our study differs from similar studies since we compared superiority and similarity of segmentectomy performed for early-stage lung cancer over lobectomy in terms of clinical and oncological results with patients who have similar homogeneous demographic and clinical features, without restrictions such as age, respiratory function reserve, and comorbidity.

\section{Materials and Methods}

\section{Patient Selection Criteria}

The data from 294 patients who underwent lobectomy and segmentectomy due to primary lung malignancy at Kocaeli University Hospital Department of Thoracic Surgery between January 2011 and May 2019 were viewed retrospectively. Ninety-nine patients who underwent lobectomy and segmentectomy due to early-stage lung adenocarcinoma with sufficient data were analyzed. Patients were divided into two groups: 84 patients undergoing lobectomy and 15 patients undergoing segmentectomy.

\section{Surgical Features}

The staging of patients was made according to the 8th TNM classification of lung cancer study group (LCSG). Patients with previous primary, synchronous or metachronous lung malignancies were excluded from the study. Transbronchial bronchoscopy, endobronchial ultrasound, and mediastinoscopy were performed for a sampling of mediastinal lymph nodes larger than $1 \mathrm{~cm}$ in computed tomography (CT) or showing uptake of standard uptake value (SUVmax) by more than 2.5 in positron emission tomography-CT (PET-CT). Operations were performed via posterolateral thoracotomy. Age, gender, smoking, disease history, respiratory parameter values, tumor size-localization-stage, lymph node involvement, postoperative complication, recurrencemetastases, death, chemoradiotherapy status, surgical margin, visceral-vascular invasion, survival, and diseasefree periods were analyzed. Physical examination and chest $\mathrm{X}$-ray follow-ups were done in the 1st and 3rd weeks after discharge. 


\section{Follow-up}

Since relapse and metastasis were considered separately, the two groups were analyzed together in order not to cause false results in statistical calculation due to their number. After resection, pathology reports were shared with the medical oncology and radiation oncology team and followed up together. Thorax CT follow-up was performed in three-month periods in the first year, sixmonth periods in the second year, and then annually. Abdominal ultrasound (USG), and abdominal CT examinations were performed.

\section{Statistical Analysis}

Statistical evaluation was performed using IBM SPSS 20.0 (SPSS Inc., Chicago, IL, USA). The normal distribution fitness was assessed using the Shapiro-Wilk and Kolmogorov-Smirnov tests. Also, normal P-P plots were used to check the normality assumption. Numerical variables with normal distribution are presented as mean \pm standard deviation, and numerical variables without normal distribution as median (25th to 75 th percentile). Categorical variables are presented using frequency (percentages). Comparisons of continuous variables between groups were carried out using independent samples $t$ test or Mann-Whitney $U$ test. Relationships between categorical variables were analyzed using chisquare test. The Kaplan-Meier method was used for survival analysis, and the log-rank test was used for multiple comparisons. Also, a Cox regression model were used for survival analysis. The origin time in survival analysis was decided as the first day of operation. Statistical analyses were carried out with $5 \%$ significance; $P<0.05$ was considered to be statistically significant.
Results

\section{Results Based on General Demographic Features}

Lobectomy was performed in $84(84.8 \%)$ patients and segmentectomy in $15(15.2 \%)$ patients. The mean age was $59.81 \pm 7.43$ years $(P=0.434)$. Eighty-four patients $(84.8 \%)$ had a smoking history $(P=0.049)$.

There was no statistically significant difference between the two groups in term of gender distribution, history of disease, or values of respiratory parameters (FEV-1, DLCO) (Table 1).

\section{Tumor Features}

The mean tumor size in the lobectomy group was $2.5 \mathrm{~cm}$, while in the segmentectomy group, it was $1.7 \mathrm{~cm}$. In 13 patients (13.1\%), surgical margin was closer than $1 \mathrm{~cm}$.

There was no statistically significant difference between the two groups in term of localization, visceral and vascular invasion, lymph node metastasis, $\mathrm{T}$ stage and disease stage (Table 2).

\section{Surgical Follow-Up Results}

While the mean discharge time was $10.12 \pm 6.22$ days, it was 10.5 days in the lobectomy group, and 8 days in the segmentectomy group $(P=0.011)$.

There was no statistically significant difference between the two groups in term of postoperative respiratory system complications, mean drain termination day, recurrencemetastasis, chemotherapy and radiotherapy status, and surgical mortality (Table 3 ).

\section{Survival, Disease-Free Time Results}

The median (interquartile range) for follow-up time was obtained at 38 (16-66) months. There was no statistically

Table 1. General Characteristic

\begin{tabular}{|c|c|c|c|c|c|c|c|}
\hline \multirow{2}{*}{ Characteristic } & & \multirow{2}{*}{ Total $(n=99)$} & \multirow{2}{*}{$\begin{array}{c}\text { Group-1 }(n=84) \\
\quad \text { (Lobectomy) }\end{array}$} & \multirow{2}{*}{$\begin{array}{l}\text { Group-2 }(n=15) \\
\text { (Segmentectomy) }\end{array}$} & \multicolumn{2}{|c|}{ Association Measures } & \multirow{2}{*}{$P$} \\
\hline & & & & & MD-OR-HR & Lower/Upper ${ }^{\mathrm{d}}$ & \\
\hline Age $($ mean $\pm S D)$ & & $59.81 \pm 7.43$ & $59.56 \pm 7.17$ & $61.20 \pm 8.93$ & $-1.64^{x}$ & $-5.79 / 2.51$ & $0.434^{\mathrm{a}}$ \\
\hline \multirow{2}{*}{ Gender } & Male $(n, \%)$ & $81(81.8 \%)$ & $71(87.7 \%)$ & $13(72.2 \%)$ & \multirow{2}{*}{$0.366^{y}$} & \multirow{2}{*}{$0.11 / 1.25$} & \multirow{2}{*}{$0.141^{c}$} \\
\hline & Female $(n, \%)$ & $18(18.2 \%)$ & $10(12.3 \%)$ & $5(27.8 \%)$ & & & \\
\hline Smooking histor & $y(n, \%)$ & $84(84.8 \%)$ & $74(88.1 \%)$ & $10(66.7 \%)$ & $0.27 y$ & $0.08 / 0.95$ & $0.049^{c}$ \\
\hline \multirow{4}{*}{ Disease history } & Absent (n,\%) & $36(36.4 \%)$ & $32(38.1 \%)$ & $4(26.7 \%)$ & \multirow{4}{*}{$1.71^{y}$} & \multirow{4}{*}{$0.34 / 8.69$} & \multirow{4}{*}{$0.409^{c}$} \\
\hline & Pulmonary $(\mathrm{n}, \%)$ & $17(17.2 \%)$ & $14(16.7 \%)$ & $3(20 \%)$ & & & \\
\hline & Cardiovasculer $(\mathrm{n}, \%)$ & $33(33.3 \%)$ & $29(34.5 \%)$ & $4(26.7 \%)$ & & & \\
\hline & Others $(\mathrm{n}, \%)$ & $11(11.1 \%)$ & $8(9.5 \%)$ & $3(20 \%)$ & & & \\
\hline \multirow{2}{*}{$\begin{array}{l}\text { Respiratory } \\
\text { function } \\
\text { values }\end{array}$} & $\mathrm{FEV}-1(\operatorname{mean} \pm \mathrm{SD}) / \mathrm{lt}$ & $2.51 \pm 0.661$ & $\begin{array}{l}2.53 \pm 0.65 \\
(1.29-3.86) \\
\end{array}$ & $\begin{array}{l}2.37 \pm 0.71 \\
(1.39-3.85) \\
\end{array}$ & $0.16^{x}$ & $-0.22 / 0.54$ & $0.402^{a}$ \\
\hline & $\begin{array}{l}\text { DLCO } \\
\text { Median(Q1-Q3) } \\
\mathrm{mL} / \mathrm{mm} \mathrm{Hg/min}\end{array}$ & $74.1 \pm 23.34$ & $66.50(36-139)$ & $81(56-136)$ & $-10.13^{x}$ & $-25.16 / 4.90$ & $0.218^{b}$ \\
\hline
\end{tabular}

n, number; It, liter; SD, standart deviation; MD, Mean/Median differences (x); Q1-Q3, 25th-75th percentile; OR, Odds ratios (y); HR, Hazard ratios $(\mathrm{z}) ; \mathrm{mL} / \mathrm{mm} \mathrm{Hg} / \mathrm{min}$, milliliter/millimeter $\mathrm{Hg} /$ minute.

andependent samples $t$ test.

${ }^{\mathrm{b}}$ Mann-Whitney U test.

${ }^{c}$ Chi-square test.

d95\% confidence intervals. 
Table 2. Tumor Features.

\begin{tabular}{|c|c|c|c|c|c|c|}
\hline \multirow{2}{*}{ Tumor features } & \multirow{2}{*}{ Total $(n=99)$} & \multirow{2}{*}{$\begin{array}{l}\text { Group-1 }(n=84) \\
\quad(\text { Lobectomy) }\end{array}$} & \multirow{2}{*}{$\begin{array}{l}\text { Group-2 }(n=15) \\
\text { (Segmentectomy) }\end{array}$} & \multicolumn{2}{|c|}{ Association measures } & \multirow{2}{*}{$P$ value } \\
\hline & & & & MD-OR-HR & Lower/Upper ${ }^{\mathrm{d}}$ & \\
\hline \multicolumn{6}{|l|}{ Localization } & \multirow{11}{*}{$0.158^{c}$} \\
\hline Right upper lobe (n, \%) & $35(35.4 \%)$ & $30(35.7 \%)$ & $5(33.3 \%)$ & - & - & \\
\hline Right middle lobe (n, \%) & $6(6.1 \%)$ & $6(7.1 \%)$ & 0 & - & - & \\
\hline Right lower lobe (n, \%) & $24(24.2 \%)$ & $17(20.2 \%)$ & $7(46.7 \%)$ & - & - & \\
\hline Left upper lobe $(\mathrm{n}, \%)$ & $26(26.3 \%)$ & $23(27.4 \%)$ & $3(20 \%)$ & - & - & \\
\hline Left lower lobe (n, \%) & $8(8.1 \%)$ & $8(9.5 \%)$ & 0 & - & - & \\
\hline Segmnet (lingula) & - & - & $1(6.7 \%)$ & - & - & \\
\hline Segmnet (right lower lobe superior) & - & - & $7(46.7 \%)$ & - & - & \\
\hline Segmnet (right upper lobe apical) & - & - & $4(26.7 \%)$ & - & - & \\
\hline Segmnet (left upper lobe apical) & - & - & $2(13.3 \%)$ & - & - & \\
\hline Segmnet (right upper lobe posterior) & - & - & $1(6.7 \%)$ & - & - & \\
\hline Tumor size (cm) Median (Q1-Q3) & - & $2.5(1.7-3.85)$ & $1.7(1.5-2.5)$ & $0.91^{\mathrm{x}}$ & $0.45 / 1.38$ & $0.024^{\mathrm{b}}$ \\
\hline Surgical margin & & & & $4.75^{y}$ & $1.30 / 17.38$ & $0.025^{c}$ \\
\hline Surgical Margin $<1 \mathrm{~cm}(\mathrm{n}, \%)$ & $13(13.1 \%)$ & $8(9.5 \%)$ & $5(33.3 \%)$ & - & - & 0.025 \\
\hline Visceral invasion $(\mathrm{n}, \%)$ & $17(17.2 \%)$ & $15(17.9 \%)$ & $2(13.3 \%)$ & $0.71^{y}$ & $0.14 / 3.47$ & $1^{c}$ \\
\hline Vascular invasion $(\mathrm{n}, \%)$ & $7(7.1 \%)$ & $7(8.3 \%)$ & $0(0 \%)$ & $0^{y}$ & - & $0.59^{c}$ \\
\hline \multicolumn{6}{|l|}{$\mathrm{T}$} & \multirow{7}{*}{$0.854^{c}$} \\
\hline $1 \mathrm{a}(\mathrm{n}, \%)$ & $6(6.1 \%)$ & $5(6 \%)$ & $1(6.7 \%)$ & - & - & \\
\hline $1 b(n, \%)$ & $29(29.3 \%)$ & $20(23.8 \%)$ & $9(60 \%)$ & - & - & \\
\hline $1 \mathrm{c}(\mathrm{n}, \%)$ & $12(12.1 \%)$ & $9(10.7 \%)$ & $3(20 \%)$ & - & - & \\
\hline $2 a(n, \%)$ & $30(30.3 \%)$ & $29(34.5 \%)$ & $1(6.7 \%)$ & - & - & \\
\hline $2 b(n, \%)$ & $6(6.1 \%)$ & $6(7.1 \%)$ & 0 & - & - & \\
\hline $3(\mathrm{n}, \%)$ & $16(16.2 \%)$ & $15(17.9 \%)$ & $1(6.7 \%)$ & - & - & \\
\hline N1 (n, \%) & $14(14.1 \%)$ & $12(14.3 \%)$ & $2(13.3 \%)$ & $0.92^{y}$ & $0.19 / 4.61$ & $1^{c}$ \\
\hline Stage & & & & $0.41^{y}$ & $0.40 / 4.21$ & \multirow{5}{*}{$0.053^{c}$} \\
\hline $1 \mathrm{a}^{*}(\mathrm{n}, \%)$ & $41(41.4 \%)$ & $30(35.7 \%)$ & $11(73.3 \%)$ & - & - & \\
\hline $1 \mathrm{~b}(\mathrm{n}, \%)$ & $23(23.2 \%)$ & $22(26.2 \%)$ & $1(6.7 \%)$ & - & - & \\
\hline $2 \mathrm{a}(\mathrm{n}, \%)$ & $5(5.1 \%)$ & $5(6 \%)$ & $0(0 \%)$ & - & - & \\
\hline $2 b(n, \%)$ & $30(30.3 \%)$ & $27(32.1 \%)$ & $3(20 \%)$ & - & - & \\
\hline
\end{tabular}

Q1-Q3, 25th-75th percentile; MD, Mean/ Median differences (x); n, number; OR, odds ratios (y); HR, hazard ratios (z).

a Independent samples $t$ test.

${ }^{\mathrm{b}}$ Mann-Whitney U test.

${ }^{\mathrm{C}}$ Chi-square test.

d $95 \%$ confidence intervals.

*1a (1-2-3) waived in 1a.

significant difference between the two groups in term of estimated survival (Figure 1) and DFT $(P=0.461)$.

In the non-parametric correlation test, there was a statistically insignificant inverse relationship between the increase in tumor size and estimated survival in both groups $(\mathrm{r}=-0.021, P=0.853$; and $\mathrm{r}=-0.264, P=0.3341$, respectively) (Figure 1). There was no censoring due to loss-to-follow-up, and there was no condition that created competing risks.

There were 34 patients (40.48\%) in the lobectomy group, and 10 patients $(66.67 \%)$ in the segmentectomy group with a tumor size of $2 \mathrm{~cm}$ or less. In terms of estimated survival, there was no statistically significant difference $(P$ $=0.572$ ). (Figure 1) The estimated disease-free time for all tumors of $2 \mathrm{~cm}$ or less was $67.70 \pm 6.62$ months $(P=$
0.343) (Figure 1).

There was no statistically significant difference between the smoking and non-smoking groups, surgical margin $1 \leq \mathrm{cm}$ and $<1 \mathrm{~cm}$ groups, visceral-pleural invasion and without invasion groups, and with and without lymph node metastasis groups in terms of estimated survival and estimated disease-free time (Table 4; Figure 1).

Since tumor size, surgical margin, and lobectomysegmentectomy techniques are parameters that affect survival, and since there are multiple parameters, multivariable Cox regressions were used and these parameters were used when building the model.

The proportional test was not statistically significant for any of the covariates (tumor size $[P=0.94]$, surgical border $[P=1.00]$, lobectomy \& segmentectomy $[P=0.60])$, 
Table 3. Features Based on Surgical Follow-up

\begin{tabular}{|c|c|c|c|c|c|c|}
\hline \multirow{2}{*}{ Features } & \multirow{2}{*}{$\begin{array}{c}\text { Total } \\
(\mathrm{n}=99)\end{array}$} & \multirow{2}{*}{$\begin{array}{c}\text { Group-1 }(n=84) \\
\text { (Lobectomy) }\end{array}$} & \multirow{2}{*}{$\begin{array}{l}\text { Group-2 }(n=15) \\
\text { (Segmentectomy) }\end{array}$} & \multicolumn{2}{|c|}{ Association Measures } & \multirow{2}{*}{$\boldsymbol{P}$} \\
\hline & & & & MD-OR-HR & Lower/Upperg & \\
\hline \multicolumn{7}{|l|}{ Post operative complications } \\
\hline Absent (n, \%) & $63(63.65)$ & $52(61.9 \%)$ & $11(73.3 \%)$ & & & \\
\hline Air leak (n, \%) & $15(15.2 \%)$ & $13(15.5 \%)$ & $2(13.3 \%)$ & & & \\
\hline Expansion defect $(\mathrm{n}, \%)$ & $11(11.1 \%)$ & $10(11.9 \%)$ & $1(6.7 \%)$ & & & \\
\hline Atelectasis (n, \%) & $2(2 \%)$ & $2(2.4 \%)$ & 0 & & & \\
\hline Arryhthmia (n, \%) & $1(1 \%)$ & $1(1.2 \%)$ & 0 & & & \\
\hline Pneumonia (n, \%) & $2(2 \%)$ & $2(2.4 \%)$ & 0 & & & \\
\hline Low hemogram (n, \%) & $4(4 \%)$ & $3(3.6 \%)$ & $1(6.7 \%)$ & & & \\
\hline Pulmonary embolism (n, \%) & $1(1 \%)$ & $1(1.2 \%)$ & - & & & \\
\hline Pulmonary system & - & $25(29.8 \%)$ & $3(20 \%)$ & $0.59^{y}$ & $0.15 / 2.27$ & $0.546^{c}$ \\
\hline Drain termination time median (Q1-Q3) (day) & 9 & $9.5(4-35)$ & $7(3-15)$ & $3.42^{x}$ & $0.32 / 6.68$ & $0.333^{\mathrm{b}}$ \\
\hline Discharget time median (Q1-Q3) (day) & 10 & $10.5(5-38)$ & $8(4-16)$ & $3.78^{x}$ & $0.39 / 7.18$ & $0.011^{\mathrm{b}}$ \\
\hline Recurrence or metastasis $(n, \%)$ & $28(28.3 \%)$ & $23(27.4 \%)$ & $5(33.3 \%)$ & $1.32^{y}$ & $0.41 / 4.30$ & $0.757^{c}$ \\
\hline Chemotherapy $(\mathrm{n}, \%)$ & $52(52.5 \%)$ & $47(56 \%)$ & $5(33.3 \%)$ & $0.39^{y}$ & $0.12 / 1.25$ & $0.182^{\mathrm{c}}$ \\
\hline Radiotherapy $(\mathrm{n}, \%)$ & $24(24.2 \%)$ & $22(26.2 \%)$ & $2(13.3 \%)$ & $0.43^{y}$ & $0.09 / 2.08$ & $0.349^{c}$ \\
\hline Mortality $(n, \%)$ & $21(21.2 \%)$ & $18(21.4 \%)$ & $3(20 \%)$ & $0.91^{y}$ & $0.23 / 3.60$ & $1^{\mathrm{c}}$ \\
\hline
\end{tabular}

Q1-Q3: 25th-75th percentile; n, number; MD, Mean/Median differences (x); OR, Odds ratios (y); HR, hazard ratios (z).

${ }^{a}$ Independent samples $t$ test.

${ }^{\mathrm{b}}$ Mann-Whitney $U$ test.

${ }^{\mathrm{c}}$ Chi-square test.

d $95 \%$ confidence intervals

Table 4. Survival, Disease-Free Time Results

\begin{tabular}{|c|c|c|c|c|}
\hline Features & Total $(n=99)$ & $\begin{array}{c}\begin{array}{c}\text { Group-1 }(n=84) \\
(\text { Lobectomy) }\end{array} \\
\end{array}$ & $\begin{array}{l}\text { Group-2 }(n=15) \\
\text { (Segmentectomy) }\end{array}$ & $\boldsymbol{P}$ \\
\hline \multicolumn{5}{|l|}{ Estitime overall survival } \\
\hline 2 Years (\%) & - & $87.80 \%$ & $66.70 \%$ & \multirow{3}{*}{$0.668^{\mathrm{a}}$} \\
\hline 5 Years (\%) & - & $63.50 \%$ & - & \\
\hline Mean \pm SD & $79.91 \pm 4.58$ & $78.41 \pm 4.742$ & $62.88 \pm 14.08$ & \\
\hline \multicolumn{5}{|l|}{ Estitime disease free time } \\
\hline Smooking group & - & $71.53 \pm 4.93$ & - & \multirow[t]{2}{*}{$0.922^{\mathrm{a}}$} \\
\hline Non -smooking group & - & $70.85 \pm 10.20$ & - & \\
\hline \multicolumn{5}{|l|}{ Disease Free time \& Surgical Margin } \\
\hline$<1 \mathrm{~cm}(\mathrm{n}: 13)($ Month $)($ Mean $\pm \mathrm{SD})$ & $42.30 \pm 5.93$ & $47.87 \pm 4.01$ & $20 \pm 0$ & $0.046^{\mathrm{a}}$ \\
\hline$\geq 1 \mathrm{~cm}$ (n:86) (Month) (Mean \pm SD) & $72.74 \pm 4.71$ & $74.96 \pm 4.85$ & $56.44 \pm 16.04$ & $0.054^{\mathrm{a}}$ \\
\hline \multicolumn{5}{|l|}{ Disease free time \& visceral invasion } \\
\hline Positive (month) (Mean $\pm \mathrm{SD}$ ) & $61.72 \pm 8.85$ & - & - & \multirow[t]{2}{*}{$0.485^{\mathrm{a}}$} \\
\hline Negative (month) (Mean \pm SD) & $73.34 \pm 5.08$ & - & - & \\
\hline Positive N1 lymph node (n:14) & & - & - & \multirow{2}{*}{-} \\
\hline 2 years survival $(\%)$ & $76,20 \%$ & - & - & \\
\hline Estitime overall survival (month) (Mean \pm SD) & $75.45 \pm 9.96$ & - & - & $0.892^{\mathrm{a} *}$ \\
\hline Estitime disease free time (month) $($ Mean $\pm \mathrm{SD})$ & $56.23 \pm 10.25$ & - & - & $0.120^{\mathrm{a} *}$ \\
\hline Estitime 2 years disease free time $(\%)$ & $70.70 \%$ & - & - & - \\
\hline Multivariable Modeling Analysis (Cox Regression) & Odds Ratio & Lower /Upperc & & \\
\hline Survival (tumor size) & 1.51 & $0.59 / 3.85$ & & $0.394^{b}$ \\
\hline Survival (surgical margin) & 0.51 & $0.07 / 3.99$ & & $0.522^{b}$ \\
\hline Survival (lobectomy versus segmnetectomy) & 0.22 & $0.60 / 8.87$ & & $0.224^{b}$ \\
\hline Disease free time (tumor size) & 0.88 & $0.41 / 1.90$ & & $0.745^{\mathrm{b}}$ \\
\hline Disease free time (surgical margin) & 1.25 & $0.36 / 4.36$ & & $0.723^{b}$ \\
\hline Disease free time (lobectomy versus segmnetectomy) & 2.63 & $0.91 / 7.56$ & & $0.073^{b}$ \\
\hline
\end{tabular}

SD, Standard deviation; $n$, number.

a Kaplan-Meier method.

${ }^{\mathrm{b}}$ Cox regression analysis.

c 95\% confidence intervals.

"Versus negative group. 

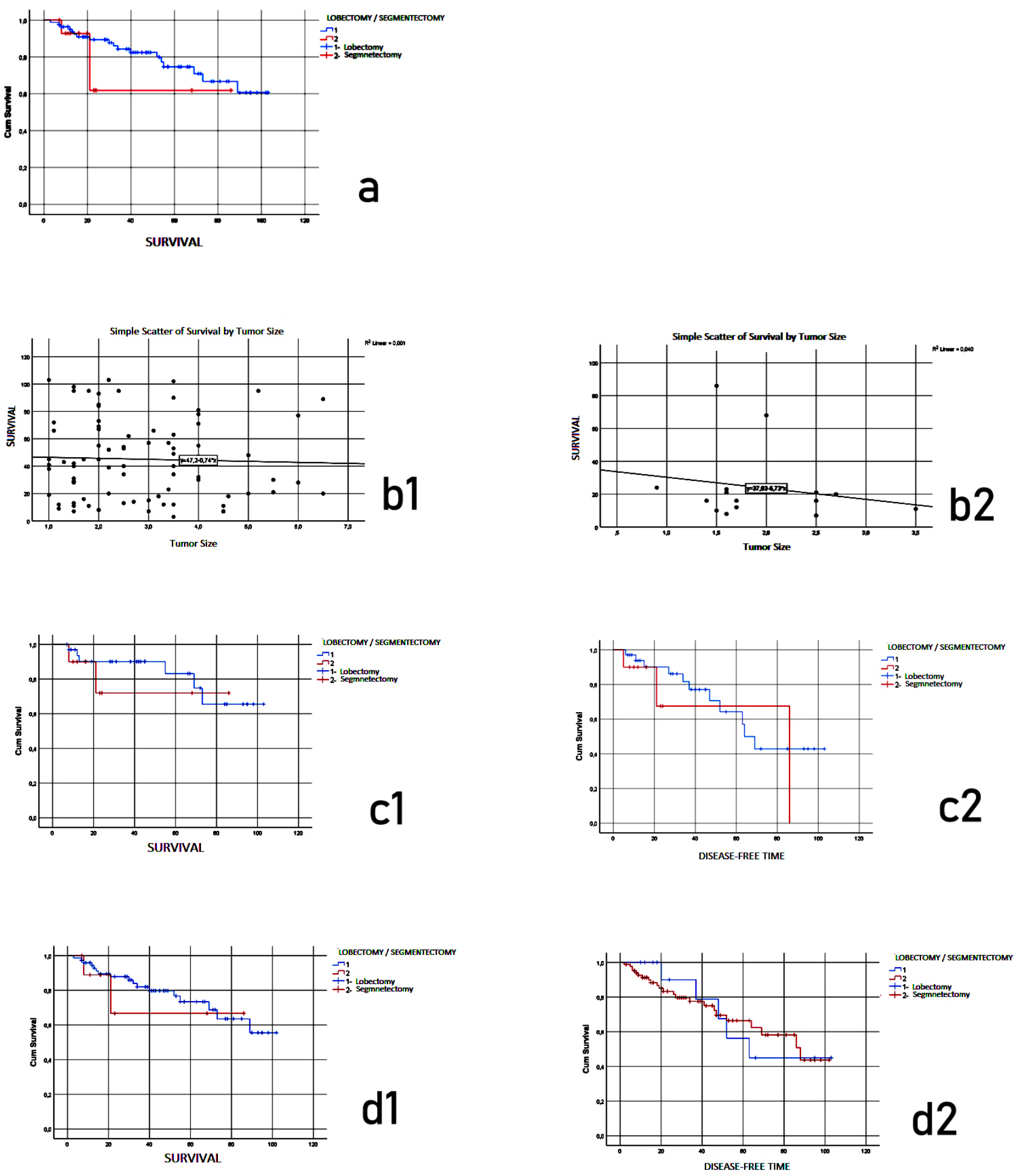

Figure 1. a: Overall survival for all patients; b: Tumor size and survival relationship, b1) Lobectomy b2) Segmentectomy; c1: Comparison of lobectomy-segmentectomy survival in tumor size $2 \mathrm{~cm}$ or less; c2: Comparison of lobectomy-segmentectomy disease-free survival in tumor size of $2 \mathrm{~cm}$ or less; $\mathrm{d} 1$ : Comparison of survival in lobectomy/segmentectomy groups in smoking patients; d2: Comparison of disease free life in lobectomy/segmentectomy groups in smoking patients; e1: Comparison of disease-free time between lobectomy/segmentectomy groups in patients with a surgical margin of $1 \mathrm{~cm}$ and longer; e2: Comparison of disease-free time between lobectomy/segmentectomy groups in patients with a surgical margin less than 1 $\mathrm{cm}$; $\mathrm{f}$ : Comparison of estimated disease-free time in patients with/without visceral pleural invasion; g1: Survival comparison between patients with and without lymph node metastasis; g2: Comparison of disease-free time between patients with and without lymph node metastasis. 

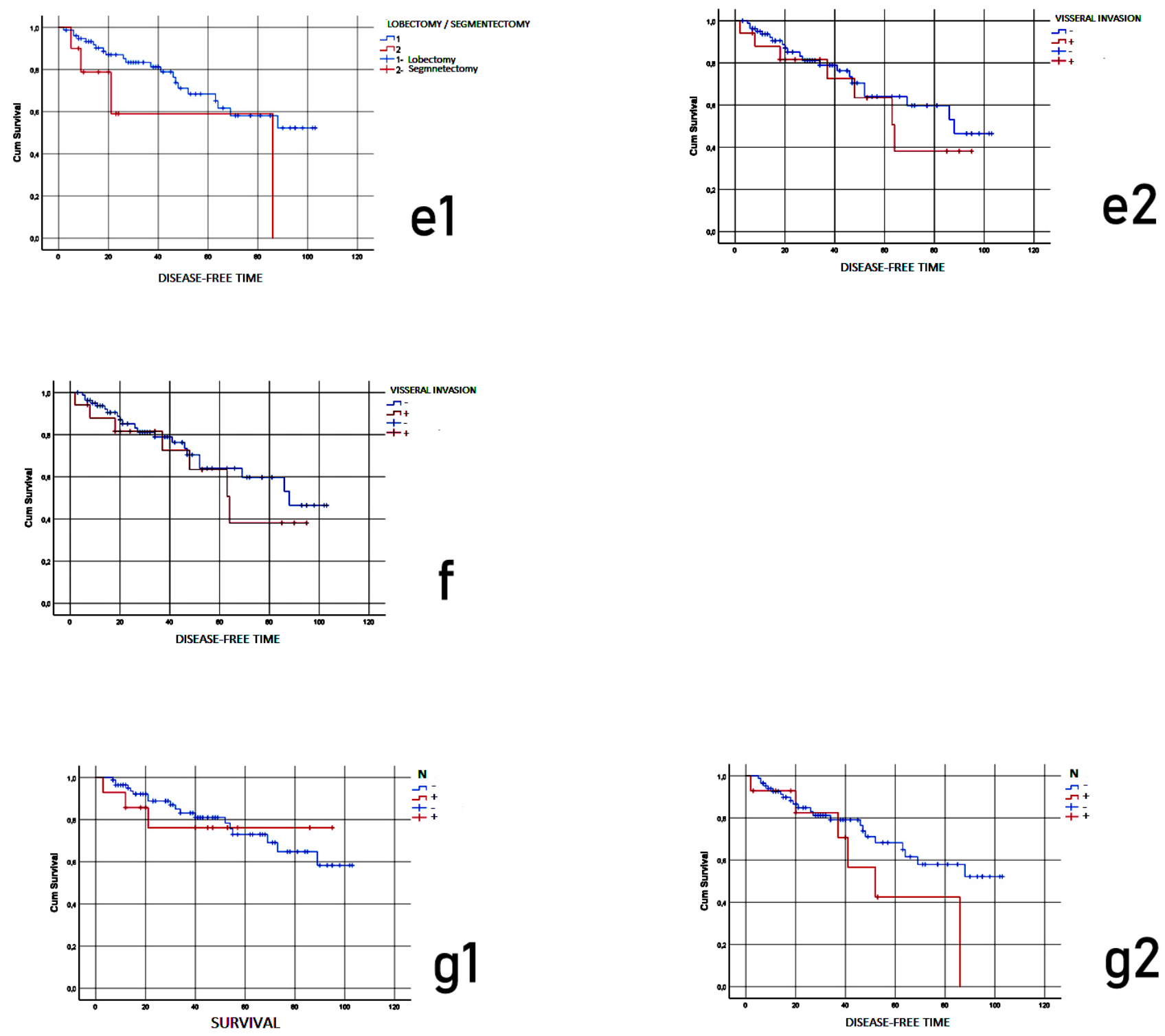

\section{Figure 1. Continued}

and the global test $(P=0.96)$ was also not statistically significant. Therefore, we could assume proportional hazards.

In multivariable modeling (Cox regression) analysis, there was no statistically significant difference in terms of mortality between tumor size $>2 \mathrm{~cm}$ and less groups $(P=0.394)$, surgical border $\leq 1 \mathrm{~cm}$ and long groups $(P$ $=0.522)$, and lobectomy and segmentectomy groups $(P=$ 0.224) (Table 4).

\section{Discussion}

In a study comparing lobectomy and sublobar resections for early stage lung cancer published by LCSG in 1995, more local recurrence and shorter survival was detected in sublobar resections. After similar results in recent studies, lobectomy has been accepted as the standard surgical treatment for early-stage lung cancer. ${ }^{10}$ Recently, with improvements in radiological imaging methods, the detection of small-sized tumors has increased. Therefore, the role of segmentectomy in surgical treatment has become controversial. In many retrospective studies, it has been reported that sublobar resection will be sufficient for the surgical treatment of early stage nonsmall cell lung cancers. ${ }^{11}$ In advocating the applicability of segmentectomy, two issues stand out: the first is evidence of low morbidity, and the second is evidence of survival equivalent to lobectomy. ${ }^{12}$

Some studies on segmentectomy and lobectomy have particularly focused on respiratory functions ${ }^{13}$ and they have been considered independent of histopathological subtyping. In addition, it is seen that the effect of chemoradiotherapy on survival and morbidity has not been examined in most studies in the literature. Our study was conducted on demographics, disease history, respiratory parameters, tumor sizes, lymphovascular involvement, and phases of similar homogeneous groups. In our study, the adenocarcinoma group, which is the most common non-small cell lung cancer type, was taken into consideration and a comparison was made between patients whose respiratory and cardiac conditions were 
sufficient for lobectomy. Our follow-up period was greater than similar studies in the literature and also postoperative chemoradiotherapy conditions were taken into consideration. In our study, the only factor that could be considered to give advantage to the segmentectomy group was the history of smoking. While smoking history was lower in the segmentectomy group and this situation was estimated to make a significant statistical difference between survival and disease-free periods, it did not make a statistical difference.

A study of LCSG compared segmentectomy and lobectomy, reporting complications requiring mechanical ventilation in the postoperative period in the lobectomy group. ${ }^{14}$ Similarly, there are studies on segmentectomy that show lower postoperative morbidity or no difference between lobectomy and segmentectomy. ${ }^{10,14,15}$ In a study by Chiang et $\mathrm{al},{ }^{16}$ the most frequent complications associated with the respiratory system were postoperative complications $(5.3 \%$ in the lobectomy group, $2.6 \%$ in the segmentectomy group), and there was no statistical difference between the two groups. In contrast, there are studies reporting a higher rate of postoperative morbidity in the segmentectomy group. ${ }^{17}$ Similar to the literature, we found the most common (80\%) postoperative complications to be related to the respiratory system. There was no difference in postoperative morbidity, complications $(P=0.546$, odds ratio $=0.59)$ and mortality rate $(P=1.00$, odds ratio $=0.91)$ between the groups.

In a study by Stamatis et al, ${ }^{14}$ it was reported that there was no difference between segmentectomy and lobectomy regarding hospital stay time. In contrast, there are studies reporting that the segmentectomy group have a shorter hospital stay. ${ }^{4,18}$ In a study by Chiang et al, ${ }^{16}$ the reported durations of chest drain and hospital stay time were shorter in the segmentectomy group. In our study, the mean hospital stay was statistically significantly shorter in the segmentectomy group $(P=0.011$, mean difference $=3.78)$. Similarly, drain termination time in the segmentectomy group was shorter than the lobectomy group. Perhaps, in the segmentectomy group, drain termination time might be expected to be shorter, but the habits we had from the lobectomy group might have delayed drain termination.

In the literature, researchers generally focus on survival and disease-free time. ${ }^{15}$ It is reported that oncological results similar to lobectomy were obtained with segmentectomy for the surgical treatment of early stage non-small cell lung cancer. ${ }^{1-3,6,7,11}$ Segmentectomy may be an alternative to lobectomy in non-small cell lung cancers, even for the medical condition of the patient who is suitable for lobectomy, ${ }^{7,8}$ or segmentectomy may be an alternative to lobectomy in selected patients. ${ }^{1,3,19,20}$

In a study by Yamato et al, ${ }^{21}$ on histopathological subtype lung adenocarcinoma as in our study, 5-year survival was $87.5 \%$ in the segmentectomy group and $85.5 \%$ in the lobectomy group. In two studies comparing lobectomy with sublobar resections for adenocarcinomas smaller than $2 \mathrm{~cm}$, the survival rate of segmentectomy was similar to lobectomy. ${ }^{2}$ In a study by Okada et al, ${ }^{22}$ the estimated 5 -year survival was $87.1 \%$ in the segmentectomy group and $87.7 \%$ in the lobectomy group. In a study by Chiang et al, ${ }^{16}$ on early-stage lung cancer resections smaller than 2 $\mathrm{cm}, 3$-year survival was $98.9 \%$ and there was no statistical difference between the segmentectomy and lobectomy groups; 3-year disease-free period was $89.9 \%$ and 3-year disease-free period in the segmentectomy group (95.1\%) was reported be better than the lobectomy group (83.5\%). In the same study, sublobar resections were reported to have a better disease-free time compared to lobectomy in resections for adenocarcinoma. ${ }^{16}$ In a study by Carr et $\mathrm{al}^{23}$ the segmentectomy and lobectomy groups of patients in stage 1a respectively showed $14 \%-14.7 \%(P=1.00)$ recurrence, 90\%-91\% 5-year survival $(P=0.984), 1.1 \%$ $1.2 \%$ mortality; for stage 1a lung tumors, the reported recurrence and survival of segmentectomy were similar to lobectomy. In a meta-analysis on early-stage non-small cell lung cancer, the results of 7 studies were included in the calculation and 5-year survival was not significantly different between the lobectomy and segmentectomy groups. ${ }^{15}$ In the same study, disease-free periods were evaluated and no statistically significant difference was observed between the lobectomy and segmentectomy groups. In a study by Tan et al, ${ }^{17}$ segmentectomy and lobectomy were reported to be similar in recurrence rate and 5-year survival. In our study, 5-year survival was estimated at $61.9 \%$ in the segmentectomy group, and $70.9 \%$ in the lobectomy group $(P=0.361$, odds ratio $=$ $0.22)$. No difference was observed between the two groups in terms of recurrence or metastasis $(P=0.757$, odds ratio $=1.32$ ). Estimated disease-free time was $69.83 \pm 7.16$ months in the lobectomy group and $63.27 \pm 17.24$ months in the segmentectomy group $(P=0.334$, odds ratio $=2.63)$.

In most studies, no information about adjuvant chemotherapy was given in the follow-up of patients. In a study by Roman et al, there was no difference in adjuvant chemotherapy. ${ }^{1}$ In our study, no difference was observed between groups in postoperative chemotherapy or radiotherapy $(P=0.182$ and $P=0.349$, respectively; odds ratio $=0.39)$.

The effect of lymph node metastasis on prognosis is important. In our study, it was observed that lymph node metastasis did not affect survival and disease-free time. The reason for this observation may be the fact that in our study, which included early-stage, small size lung tumors, a small number of patients had lymph node metastasis and almost all of these metastases were N1.

In lung resections, keeping surgical margin as long as possible will be the optimal approach. ${ }^{24}$ In a segmentectomy study performed by Nomori et al, ${ }^{6}$ the surgical margin was $2 \mathrm{~cm}$ and above, and 5-year diseasefree time was $95 \%$ in $2 \mathrm{~cm}$ and small tumors. In a study by El-Sherif et al, ${ }^{25}$ on patients who underwent sublobar resection due to early-stage lung cancer, in 20-month follow-up, recurrence in the group with a surgical margin of less than $1 \mathrm{~cm}$ was reported to be significantly higher 
statistically, compared to the group with a surgical margin of $1 \mathrm{~cm}$ or more. In our study, groups were similar in terms of visceral-lymphovascular invasion. There was no difference between the lobectomy and segmentectomy groups in terms of the estimated survival in patients with a distance of $1 \mathrm{~cm}$ or more from surgical border $(P=0.054)$. Recurrence-metastasis rate was higher in patients who underwent segmentectomy compared to patients with a surgical margin of less than $1 \mathrm{~cm}(P=0.025)$ and diseasefree time in the segmentectomy group was statistically significantly shorter than the lobectomy group $(P=0.046)$.

Considering the information in the literature overall, the advantages of segmentectomy are that it results in less morbidity and disability while yielding oncological results similar to lobectomy, ${ }^{2,6}$ and is associated with higher quality of life than lobectomy in the post-operative period. In addition, due to less loss of respiratory function, ${ }^{19,20}$ it can be used for patients whose respiratory and cardiopulmonary status is borderline. ${ }^{3,6}$ Another positive aspect is the advantage of synchronous, metachronous and 2nd primary lung cancer in terms of suitability for operation. ${ }^{6,12,13,16,22}$ In the near future, segmentectomy may be thought close to lobectomy as the standard treatment for early non-small cell lung cancer. ${ }^{6,20}$ However, lobectomy raises doubts about lower recurrence and longer disease-free survival. Future studies will provide more permanent approaches in the selection of lobectomy versus segmentectomy.

The weaknesses of our study include the fact that it was retrospective and the number of segmentectomy cases was limited compared to the number of lobectomies.

In early-stage small-sized lung adenocarcinomas, underestimating the effectiveness of segmentectomy, which is actually an anatomical resection, by classifying it under sublobar resections, is unjustified to segmentectomy.

In conclusion, similar surgical postoperative and oncological results were observed in patients undergoing segmentectomy and lobectomy in surgical treatment of early-stage lung adenocarcinomas. If there is no contraindication, segmentectomy can be considered as the surgical treatment for lung adenocarcinomas with a tumor size of $2 \mathrm{~cm}$ or less and with a minimum $1 \mathrm{~cm}$ clean surgical margin. Thus, loss of function in the lungs will be less, associated morbidity will be lower, and the patient will have an advantage in situations requiring lung resection in later years. Future multicenter studies are needed to support this thesis.

\section{Authors' Contribution}

HFS, AE and ST participated in the planning, execution, or analysis of the study, contributed to the design and implementation of the study and read and approved the final submitted version.

\section{Conflict of Interest Disclosures}

None of the authors have any conflict of interest.

\section{Ethical Statement}

Approval number 2020/45 was received from Kocaeli University Faculty of Medicine Ethics Committee on 04/03/2020.

\section{Funding}

There was no received financial support was received from any institution or organization.

\section{References}

1. Roman M, Labbouz S, Valtzoglou V, Ciesla A, Hawari M, Addae-Boateng E, et al. Lobectomy vs. segmentectomy. A propensity score matched comparison of outcomes. Eur J Surg Oncol. 2019;45(5):845-50. doi: 10.1016/j. ejso.2018.10.534.

2. Zhao ZR, Situ DR, Lau RWH, Mok TSK, Chen GG, Underwood MJ, et al. Comparison of segmentectomy and lobectomy in stage IA adenocarcinomas. J Thorac Oncol. 2017;12(5):890-6. doi: 10.1016/j.jtho.2017.01.012.

3. Ha KJ, Yun JK, Lee GD, Cho WC, Choi SH, Kim HR, et al. Surgical outcomes of radiographically noninvasive lung adenocarcinoma according to surgical strategy: wedge resection, segmentectomy, and lobectomy. Korean J Thorac Cardiovasc Surg. 2018;51(6):376-83. doi: 10.5090/ kjtcs.2018.51.6.376.

4. Suzuki K, Saji H, Aokage K, Watanabe SI, Okada M, Mizusawa J, et al. Comparison of pulmonary segmentectomy and lobectomy: safety results of a randomized trial. J Thorac Cardiovasc Surg. 2019;158(3):895-907. doi: 10.1016/j. jtcvs.2019.03.090.

5. Bao F, Ye P, Yang Y, Wang L, Zhang C, Lv X, et al. Segmentectomy or lobectomy for early stage lung cancer: a meta-analysis. Eur J Cardiothorac Surg. 2014;46(1):1-7. doi: 10.1093/ejcts/ezt554.

6. Villamizar N, Swanson SJ. Lobectomy vs. segmentectomy for NSCLC (T<2 cm). Ann Cardiothorac Surg. 2014;3(2):1606. doi: 10.3978/j.issn.2225-319X.2014.02.11.

7. Guo J, Liu Y, Tian X, Ren Z, Lin J, Wang B, et al. Less is more in solid-dominant lung cancer? sublobar resection versus lobectomy for solid-dominant stage IA non-smallcell lung cancer: a meta-analysis study. Mol Clin Oncol. 2019;11(5):465-73. doi: 10.3892/mco.2019.1914.

8. Tsutani Y, Kagimoto A, Handa Y, Mimae T, Miyata Y, Okada $\mathrm{M}$. Wedge resection versus segmentectomy in patients with stage I non-small-cell lung cancer unfit for lobectomy. Jpn J Clin Oncol. 2019;49(12):1134-42. doi: 10.1093/jjco/hyz122.

9. Rao S, Ye L, Min L, Zhao G, Chen Y, Huang Y, et al. Meta-analysis of segmentectomy versus lobectomy for radiologically pure solid or solid-dominant stage IA nonsmall cell lung cancer. J Cardiothorac Surg. 2019;14(1):197. doi: 10.1186/s13019-019-0996-6.

10. Schuchert MJ, Pettiford BL, Keeley S, D’Amato TA, Kilic A, Close J, et al. Anatomic segmentectomy in the treatment of stage I non-small cell lung cancer. Ann Thorac Surg. 2007;84(3):926-32; discussion 32-3. doi: 10.1016/j. athoracsur.2007.05.007.

11. Gürsoy S, Erol Y. Stereotactic BODY RADIATION THERAPY (SBRT) or surgery in early stage non-smallcell lung cancer: the surgeon's point of view. Updates On Pulmonary Diseases. 2018;6(3):114-23. doi: 10.5152/ gghs.2018.048.

12. Sihoe AD. Limited resection for lung cancer: current role. Toraks Cerrahisi Bülteni. 2012; 3(3):150-9. doi: 10.5152/ tcb.2012.24. 
13. Charloux A, Quoix E. Lung segmentectomy: does it offer a real functional benefit over lobectomy? Eur Respir Rev. 2017;26(146). doi: 10.1183/16000617.0079-2017.

14. Stamatis G, Leschber G, Schwarz B, Brintrup DL, Ose C, Weinreich G, et al. Perioperative course and quality of life in a prospective randomized multicenter phase III trial, comparing standard lobectomy versus anatomical segmentectomy in patients with non-small cell lung cancer up to $2 \mathrm{~cm}$, stage IA (7th edition of TNM staging system). Lung Cancer. 2019;138:19-26. doi: 10.1016/j. lungcan.2019.09.021.

15. Lim TY, Park S, Kang CH. A Meta-analysis comparing lobectomy versus segmentectomy in stage I non-small cell lung cancer. Korean J Thorac Cardiovasc Surg. 2019;52(4):195-204. doi: 10.5090/kitcs.2019.52.4.195.

16. Chiang XH, Hsu HH, Hsieh MS, Chang CH, Tsai TM, Liao $\mathrm{HC}$, et al. Propensity-matched analysis comparing survival after sublobar resection and lobectomy for cT1N0 lung adenocarcinoma. Ann Surg Oncol. 2020;27(3):703-15. doi: 10.1245/s10434-019-07974-9.

17. Tan Q, Huang J, Ding Z, Lin H, Lu S, Luo Q. Meta-analysis for curative effect of lobectomy and segmentectomy on nonsmall cell lung cancer. Int J Clin Exp Med. 2014;7(9):2599604.

18. Bédat B, Abdelnour-Berchtold E, Perneger T, Licker MJ, Stefani A, Krull M, et al. Comparison of postoperative complications between segmentectomy and lobectomy by video-assisted thoracic surgery: a multicenter study. J Cardiothorac Surg. 2019;14(1):189. doi: 10.1186/s13019019-1021-9.

19. Harada H, Okada M, Sakamoto T, Matsuoka H, Tsubota
N. Functional advantage after radical segmentectomy versus lobectomy for lung cancer. Ann Thorac Surg. 2005;80(6):2041-5. doi: 10.1016/j.athoracsur.2005.06.010.

20. Mimae T, Okada M. Are segmentectomy and lobectomy comparable in terms of curative intent for early stage non-small cell lung cancer? Gen Thorac Cardiovasc Surg. 2020;68(7):703-6. doi: 10.1007/s11748-019-01219-y.

21. Yamato Y, Koike T, Yoshiya K, Shinohara H, Toyabe S. Results of surgical treatment for small $(2 \mathrm{~cm}$ or under) adenocarcinomas of the lung. Surg Today. 2008;38(2):10914. doi: 10.1007/s00595-007-3594-5.

22. Okada M, Sakamoto T, Nishio W, Uchino K, Tsubota N. Characteristics and prognosis of patients after resection of nonsmall cell lung carcinoma measuring $2 \mathrm{~cm}$ or less in greatest dimension. Cancer. 2003;98(3):535-41. doi: $10.1002 /$ cncr.11530.

23. Carr SR, Schuchert MJ, Pennathur A, Wilson DO, Siegfried JM, Luketich JD, et al. Impact of tumor size on outcomes after anatomic lung resection for stage $1 \mathrm{~A}$ non-small cell lung cancer based on the current staging system. J Thorac Cardiovasc Surg. 2012;143(2):390-7. doi: 10.1016/j. jtcvs.2011.10.023.

24. Şahin M, Yenigün MB, Kocaman G, Duman E, Sakallı MA, Özkan M, et al. Sublobar resections in early-stage non-small cell lung cancer. Turk Gogus Kalp Damar Cerrahisi Derg. 2019;27(3):367-73. doi: 10.5606/tgkdc.dergisi.2019.17695.

25. El-Sherif A, Fernando HC, Santos R, Pettiford B, Luketich JD, Close JM, et al. Margin and local recurrence after sublobar resection of non-small cell lung cancer. Ann Surg Oncol. 2007;14(8):2400-5. doi: 10.1245/s10434-007-94219. 